\title{
Prevalence and predictors of metabolic syndrome among people living with human immunodeficiency virus (PLWHIV)
}

Dula Dessalegn Bosho ${ }^{1 *}$, Lemessa Dube ${ }^{2}$, Teshale Ayele Mega', Dawit Abera Adare ${ }^{3}$, Mikyas Gashaw Tesfaye ${ }^{3}$ and Tesfahun Chanie Eshetie ${ }^{1}$

\begin{abstract}
Background: Use of combination antiretroviral therapy (CART) has led to significant reductions in morbidity and mortality. However, there is a growing concern about metabolic syndromes (MS), among patients receiving cART. Despite this fact, there is limited evidence for the prevalence of the MS among HIV-infected persons receiving CART in developing countries, particularly Ethiopia.

Objective: To determine the prevalence and predictors of MS among people living with HIV/AIDS in Jimma health centre, Jimma Zone south west Ethiopia.

Methods: A cross-sectional study was conducted on people living with HIV/AIDS (PLWHA) in Jimma health centre that fulfilled the inclusion criteria. Data on demographic and anthropometric characteristics were collected using World health organization (WHO) stepwise approach. Fasting blood glucose and lipid profile was measured. The Third Report of National Cholesterol Education Program-adult treatment panel III (NCEP-ATP III)-2001, the International Diabetes Federation (IDF)-2005 and the Joint interim statement-2009 (JIS) criteria were used to define MS. Data were analyzed using statistical software package (SPSS) version 20.0. Logistic regression analysis was done to identify predictors of MS and predictors with $p$ value $<0.05$ were used to declare statistical significance.

Results: Of 268 HIV-infected participants included in the analysis, 211 (78.7\%) were women. The mean age of the participants was $39.32 \pm 10.626$ years. Using the NCEP-ATP III criteria, the prevalence of MS was found to be $23.5 \%$ (63 patients). While it was 20.5\% (55 patients) and 27.6\% (74 patients) with IDF and JIS criteria respectively. Enrollment in formal education resulted in $75 \%$ increment in the odds of $\mathrm{MS}$ ( $\mathrm{AOR}=0.25,95 \% \mathrm{Cl}[0.072-0.879])$. The odds of MS in patients with body mass index $>25 \mathrm{~kg} / \mathrm{m}^{2}$ was elevated to 13.4 times ( $A O R=13.39,95 \% \mathrm{Cl}[3.943-45.525]$ ) and exposure to D-drugs was attributed to $59 \%$ increment in the odds of $M S$ ( $A O R=1.59,95 \% \mathrm{Cl}[0.58-4.56]$ ), although the finding lacks statistical significance.
\end{abstract}

Conclusions: Metabolic syndromes was relatively common to the study population. Hence, promoting health education and monitoring patient's clinical and laboratory parameters at every visit and taking appropriate measure is ideal.

Keywords: Metabolic syndrome, HIV/AIDS, Ethiopia

\footnotetext{
*Correspondence: duladessa@gmail.com

${ }^{1}$ Department of Pharmacy, Faculty of Health Sciences, Institute of Health,

Jimma University, Jimma, Ethiopia

Full list of author information is available at the end of the article
} 


\section{Background}

Metabolic syndromes (MS) are a cluster of biochemical and anthropometric abnormality that has high predictive ability for the development of atherosclerotic cardiovascular diseases (CVD) [1]. A variety of definitions had been used with different sets of diagnostic criteria, which vary from specific principal elements. But, it generally includes hypertension, obesity, glucose intolerance, hypertriglyceridemia and high density lipoprotein (HDL) dyslipidemia [2]. It is a constellation of cardiovascular risk factors of multifactorial etiology including the use of combination antiretroviral therapy (cART) [3].

Combination antiretroviral therapy (cART) has modified the natural history of human immunodeficiency virus (HIV) infection, leading to a significant reduction in morbidity and mortality. However, long-term toxicity and variety of metabolic abnormalities including dyslipidemia, fat redistribution, high blood pressure, and insulin resistance have frequently been reported, particularly when it contains protease inhibitors [4]. There is also a growing concern that, metabolic complications associated with HIV infection such as, hypertriglyceridemia, low HDL, and weight loss, continue to occur to untreated HIV-infected patients, while lipodystrophy, obesity, hypercholesterolemia, and insulin resistance are increasingly reported among those patients receiving cART [5].

Despite measurable achievements in reducing morbidity and mortality, the cART uses had also given a rise to metabolic and morphologic abnormalities which are risk factors of CVD. Recent finding indicated that, there is a high prevalence of MS among patients receiving ART [6]. However, other data suggested that, the increased prevalence of MS among HIV-infected patients may be more reflective of the burgeoning epidemic of obesity than a predominant effect of ART [7]. Results of the Data Collection on Adverse Events of Anti-HIV Drugs (DAD) study showed that, men were more likely than women to have MS and therapy with non-nucleotides reverse transcriptase inhibitors (NNRTIs) may be protective [8].

There is limited evidence for metabolic complications and risk factors of MS in HIV-infected patients in subSaharan region, particularly in Ethiopia [9]. Therefore, this study was aimed to investigate the prevalence and predictors of MS among people living with HIV/AIDS in Jimma Health Centre, Jimma Zone South-west Ethiopia.

\section{Method and participants}

\section{Study design and study population}

This was a cross-sectional study conducted at Jimma health center. The study population was sampled HIV patients attending the clinic for follow-up and on ART. The eligibility criteria for the study participants were; patients aged $\geq 18$ years and on follow-up. We exclude patients that refused to sign informed consent or unwilling to participate and those who failed to fast for the next appointment. The health centre serves as an outpatient facility offering HIV care and treatment amongst other services. It is situated in Jimma town, $364 \mathrm{~km}$ away from the capital city, Addis Ababa and serves both rural and urban population. It provides services for around 800 HIV positive patients. The study was conducted between April 1 to May 30, 2016.

\section{Sample size calculation and selection of study participants} Sample size of 286 was estimated using a single population proportion formula with the following assumptions; $50 \%$ prevalence of metabolic syndrome among general population in Ethiopia, 5\% margin of error, 95\% confident interval and $10 \%$ for non-response. The study participants were selected using simple random sampling technique.

\section{Study variables}

Metabolic syndromes among patients receiving cART was considered as an outcome variable and patient related (age, gender, educational level, income, occupation), diseases related (co-morbidities, CD4 count, WHO staging, duration HIV since diagnosed, opportunistic infections), behavioural related (drug use, lifestyle modification) and drug/therapy related factors (concomitant drug therapy, type of cART regimens, duration of cART) were considered as predictor variables.

\section{Data collection}

An English version data collection tool adapted from WHO STEP wise approach to chronic disease risk factor surveillance $[10,11]$ and the patient charts were used to design the data collection tool. Data was collected on socio-demographic and clinical variables both from patients and their charts. The patients' charts review was followed by collecting all necessary information about the patient. Tools used to collect data on variables such as, anthropometric (weight, height, waist circumference), blood pressure, and heart rate (HR) were standardized prior to be used for actual patient data collection. All measurements were conducted under the standard operating procedure by trained nurses with strict supervision of the principal investigator.

Blood pressure (BP) was measured as the average of the last two of three measurements with the Omron Automatic Inflation Blood Pressure Monitor taken at intervals longer than 2 min after the patient had been sitting for at least $30 \mathrm{~min}$. Anthropometric measurements (waist circumference (WC) was measured with a flexible inelastic tape placed on the midpoint between the lower rib margin and the iliac crest in a perpendicular plane to the long 
axis of the body. Height was determined without shoes using a portable stadiometer. Weight was measured using a Tanita scale; patients were fully dressed, without heavy clothing or shoes). HR was recorded from the Omron Automatic Inflation Blood Pressure Monitor during blood pressure measurement. Similarly, biochemical measurements such as, fasting blood glucose (FBG), blood lipid, and creatinine were collected following laboratory standard operating procedures by a trained laboratory technologist. Blood sample was collected from each participant on the next morning after fasting for $12 \mathrm{~h}$ using vacutainer blood collection system to determine FBG and lipid profile. Five millilitre of blood was drawn from each patient's cubital vein. Laboratory analysis of sample was done by laboratory technician. Serum samples were analyzed for FBG level and lipid profile [total cholesterol (TC), high density lipoprotein-cholesterol (HDL-c), low density lipoprotein-cholesterol (LDL-c) and triglycerides (TGs)] using ABX Pentra 400 machine. Enzymatic colorimetric assay method was used for the measurement of total cholesterol (CHODPAP method) and triglyceride (GPO-PAP method), while direct homogeneous enzymatic colorimetric assay technique was utilized for the measurement of HDL-c and LDLc. FBG level was measured by glucose oxidase method (GOD-PAP).

\section{Data analysis and interpretation}

Data were cleaned, coded and entered into Epi-Data version 3.1 and exported to the Statistical package for Social Science (SPSS) version 20.0 for analysis. Descriptive statistics using frequency distribution was performed for socio-demographic, epidemiological, clinical, and laboratory values. Association for the predictors and outcome variables were assessed using Chi square test and logistic regression analysis. Multivariate analysis using logistic regression was performed to control effect of confounding variables and to identify the independent predictors of MS. Predictor variables with $\mathrm{p}$ value of $<0.05$ were used to declare statistically significance.

\section{Outcome definition}

The NCEP-ATP III 2001 guidelines define MS as having 3 or more of the following criteria: abdominal obesity (WC $\geq 102 \mathrm{~cm}$ for men and $\geq 88 \mathrm{~cm}$ for women); TG $\geq 1.7 \mathrm{mmol} / \mathrm{L} ; \mathrm{HDL}-\mathrm{c} \leq 1.03 \mathrm{mmol} / \mathrm{L}$ in men and $\leq 1.29 \mathrm{mmol} / \mathrm{L}$ in women; $\mathrm{BP} \geq 130 / 85 \mathrm{mmHg}$ or on treatment for hypertension; and FBG level of $\geq 6.1 \mathrm{mmol} / \mathrm{L}$ or on treatment for diabetes [12]. With IDF 2005-criteria, an individual is considered to have MS if $\mathrm{WC} \geq 94 \mathrm{~cm}$ for men and $\geq 80 \mathrm{~cm}$ for women plus any of two or more of the following: $\mathrm{TG} \geq 1.7 \mathrm{mmol} / \mathrm{L}$; $\mathrm{HDL}-\mathrm{c} \leq 1.03 \mathrm{mmol} / \mathrm{L}$ in men and $\leq 1.29 \mathrm{mmol} / \mathrm{L}$ in women; $\mathrm{BP} \geq 130 / 85 \mathrm{mmHg}$ or on treatment for hypertension; and FBG level of $\geq 5.6 \mathrm{mmol} / \mathrm{L}$ or on treatment for diabetes [2]. Whereas the Joint Interim Statement (JIS) criteria, defines MS as having 3 or more of the following: WC $\geq 90 \mathrm{~cm}$ for men and $\geq 80 \mathrm{~cm}$ for women; TG $\geq 1.7 \mathrm{mmol} / \mathrm{L}$ or on treatment for TGs; $\mathrm{HDL}-\mathrm{c} \leq 1.0 \mathrm{mmol} / \mathrm{L}$ in men and $\leq 1.3 \mathrm{mmol} / \mathrm{L}$ in women or on treatment for HDL-c; BP $\geq 130 / 85 \mathrm{mmHg}$ or on treatment for hypertension; and FBG level of $\geq 5.6 \mathrm{mmol} / \mathrm{L}$ or on treatment for elevated glucose will define MS [13].

\section{Results}

Of 286 HIV-infected randomly selected patients, 18 of them declined to give informed consent and were excluded from the analysis.

\section{Socio-demographic characteristics of study participants}

Among $268 \mathrm{HIV}$-infected participants included in the analysis, 211 (78.7\%) were women. The mean age of participants was $39.32 \pm 10.626$ years. Majority of them (73.5\%) were enrolled in formal education and, $64.2 \%$ of these were able to read and write. More than two-third of them (69\%) had monthly income of $\leq 500$ Ethiopian birr (ETB). About 15 (5.6\%) of the participants had history of cigarette smoking and $4(1.5 \%)$ were current smokers. Eighty-nine (33.2\%) of them had history of Khat chewing and current chewers were about 17 (6.3\%). Those with past history of alcohol consumption were about two-fifth (38.1\%) and $38(14.2 \%)$ of them currently drink alcohol 1-4 times per week. Nearly half of them (46.6\%) could get fruits 1-2 days per week and majority of them (52.6\%) were physically inactive (Table 1).

\section{Clinical and drug related characteristics}

One hundred and seventeen (43.7\%) patients had reported that their BP was measured. About $36.6 \%$ of them had their BP measured in the past 12 months. Around 17 (6.3\%) of them reported that they had been told by health care professional they had hypertension. Of these, 5 (1.9\%) were receiving anti-hypertensive medication in the past 2 weeks. About $3.4 \%$ of patients were asthmatic and $3(1.1 \%)$ had chronic kidney diseases.

Nearly half of the patients (48\%) were WHO stage 2 and majority of them (53.7\%) had lived 6 years and above with HIV/AIDS. Most of them (83.2\%) had CD4 count less than $350 \mathrm{cell} / \mathrm{mm}^{3}$ at baseline and $226(84.3 \%)$ had opportunistic infections (OIs) prior to HIV diagnosis. More than half $(52.6 \%)$ of them were receiving $\mathrm{TDF}+3 \mathrm{TC}+\mathrm{EVF}$ at base line and about $60.8 \%$ of them were taking ART for less than 5 years. Moreover, $52.6 \%$ of the participants were receiving cotrimoxazole for prevention of OIs together with cART (Table 2). 
Table 1 Socio-demographic characteristic of people living with HIV/AIDS at follow up in Jimma health centre ART clinic, April 01 to May 30, 2016

\begin{tabular}{|c|c|}
\hline Variables & Frequency, $\mathrm{N}=268(\%)$ \\
\hline \multicolumn{2}{|l|}{ Sex } \\
\hline Male & $57(21.3)$ \\
\hline Female & $211(78.7)$ \\
\hline \multicolumn{2}{|l|}{ Age (years) } \\
\hline $18-30$ & $60(22.4)$ \\
\hline $31-40$ & $109(40.7)$ \\
\hline $41-50$ & $61(22.8)$ \\
\hline$>50$ & $38(14.2)$ \\
\hline \multicolumn{2}{|l|}{ Able to write and read } \\
\hline No & $96(35.8)$ \\
\hline Yes & $172(64.2)$ \\
\hline \multicolumn{2}{|c|}{ Enrolled in formal education } \\
\hline Yes & $197(73.5)$ \\
\hline No & $71(26.5)$ \\
\hline \multicolumn{2}{|l|}{ Monthly income in ETB } \\
\hline$\leq 500$ & $185(69.0)$ \\
\hline $501-1500$ & $67(25.0)$ \\
\hline $1501-2500$ & $7(2.6)$ \\
\hline$\geq 2501$ & $9(3.4)$ \\
\hline \multicolumn{2}{|l|}{ Cigarette smoking history } \\
\hline No & $253(94.4)$ \\
\hline Yes & $15(5.6)$ \\
\hline \multicolumn{2}{|l|}{ Current smoker } \\
\hline No & $264(98.5)$ \\
\hline Yes & $4(1.5)$ \\
\hline \multicolumn{2}{|l|}{ Khat chewing history } \\
\hline No & $179(66.8)$ \\
\hline Yes & $89(33.2)$ \\
\hline \multicolumn{2}{|l|}{ Current Khat chewer } \\
\hline No & $72(26.9)$ \\
\hline Yes & $17(6.3)$ \\
\hline \multicolumn{2}{|c|}{ Current alcohol consumption } \\
\hline No & $166(61.9)$ \\
\hline Yes & $102(38.1)$ \\
\hline \multicolumn{2}{|c|}{ Frequency of alcohol drink in past 12 months } \\
\hline 4 drinks per week & $38(14.2)$ \\
\hline 2 drinks per week & $38(14.2)$ \\
\hline Less than one a month & $26(9.7)$ \\
\hline \multicolumn{2}{|l|}{ Fruit intake } \\
\hline None & $78(29.1)$ \\
\hline $1-2$ days/week & $125(46.6)$ \\
\hline 3-4 days/week & $41(15.3)$ \\
\hline 5-7 days/week & $24(9.0)$ \\
\hline \multicolumn{2}{|l|}{ Physical activity } \\
\hline Inactive & $141(52.6)$ \\
\hline Active & $127(47.4)$ \\
\hline
\end{tabular}

Table 2 Clinical and drug related characteristics of people living with HIV/AIDS at follow up in Jimma health centre ART clinic, April 01 to May 30, 2016

Variables

Frequency $\mathrm{N}=\mathbf{2 6 8}(\%)$

History of BP measured by health workers

No

$151(56.3)$

Yes

$117(43.7)$

Period of blood pressure measured

$\begin{array}{lc}\text { The past } 12 \text { months } & 98(36.6) \\ \text { Within past } 1-5 \text { years } & 16(6.0) \\ \text { More than past } 5 \text { years } & 3(1.1) \\ \text { Previous history of hypertension } & \end{array}$

$251(93.7)$

Yes

$17(6.3)$

Taking antihypertensive agent past 2 weeks

$$
\begin{array}{lr}
\text { No } & 16(4.5) \\
\text { Yes } & 5(1.9)
\end{array}
$$

Previous history of asthma

$$
\text { No } 259 \text { (96.6) }
$$$$
\text { Yes } 9 \text { (3.4) }
$$

Previous history of chronic kidney diseases

$\begin{array}{cc}\text { No } & 265(98.9) \\ \text { Yes } & 3(1.1)\end{array}$

Duration of HIV diagnosis

$$
\begin{array}{ll}
\leq 5 \text { years } & 122(45.5) \\
\geq 6 \text { years } & 146(54.5)
\end{array}
$$

CD4 (cell/ $\left./ \mathrm{mm}^{3}\right)$

$<350$

$223(83.2)$

$351-550$

$38(14.2)$

$\geq 551$

$7(2.6)$

WHO stage

$\begin{array}{lc}\text { I } & 48(17.9) \\ \text { II } & 129(48.1) \\ \text { III } & 83(31) \\ \text { IV } & 8(3)\end{array}$

Ols prior to HIV diagnosis

Yes $226(84.3)$

No $\quad 42(15.7)$

Types of CART regimes at baselines
D-drugs ${ }^{\mathrm{a}}$
$92(34.3)$
Others $^{b}$
$176(65.7)$
Duration of CART (years)

$$
\leq 5
$$

Concomitants drug use

Cotrimoxazole $141(52.6)$

$\mathrm{INH}$

ETB Ethiopian birr 
Table 2 (Continued)

\begin{tabular}{lc}
\hline Variables & Frequency $\mathbf{N}=\mathbf{2 6 8}(\%)$ \\
\hline Multivitamins & $6(2.2)$ \\
Others $^{d}$ & $13(4.9)$ \\
\hline
\end{tabular}

$B P$ blood pressure, HIV human immunodeficiency virus, $C D 4$ cluster differentiation 4, Ols opportunistic infections, URT/s upper respiratory tract infections, CART combination antiretroviral therapy, $d 4 T$ stavudine, 3TC lamivudine, AZT zidovudine, TDF tenofovir, NVP nevirapine, EVF efavirenz, INH isoniazid

${ }^{a} \mathrm{~d} 4 \mathrm{~T}+3 \mathrm{TC}+\mathrm{NVP} ; \mathrm{d} 4 \mathrm{~T}+3 \mathrm{TC}+\mathrm{EVF}$

b $\mathrm{AZT}+3 \mathrm{TC}+\mathrm{NVP} ; \mathrm{AZT}+3 \mathrm{TC}+\mathrm{EVF} ; \mathrm{TDF}+3 \mathrm{TC}+\mathrm{EVF} ; \mathrm{TDF}+3 \mathrm{TC}+\mathrm{NVP}$

c Naïve patients

d Enalapril, hydrochlorothiazide, atenolol, prednisolone, salbutamol puff

Physical, biochemical measurements and prevalence of MS Physical and biochemical measurements indicated that, nearly two-fifth $(38.4 \%)$ of the patients had hypertension and almost more than two-third of them (68.5\%) had normal body weight. About $18.7 \%$ of the patients' WC was in line with the definition of MS. HDL-c was the most prevalent components of MS 132 (49.3\%) followed by BP 103 (38.4\%). Therefore, according to NCEP-ATP III, the prevalence of MS was $63(23.5 \%)$, and it was 55 (20.5\%) according to IDF. Similarly, the prevalence of MS was 74 (27.6\%) according to JIS (Table 3$)$.

\section{Predictors of metabolic syndrome}

The result of binary logistic regression analysis of the independent predictors showed that age group

Table 3 Physical and biochemical measurements among people living with HIV/AIDS at follow up in Jimma health centre ART clinic, April 01 to May 30, 2016

\begin{tabular}{|c|c|c|}
\hline Variables & $\begin{array}{l}\text { Frequency, } N=268 \\
(\%)\end{array}$ & $\begin{array}{l}\text { Components } \\
\text { of MS }\end{array}$ \\
\hline \multicolumn{3}{|l|}{ Blood pressure } \\
\hline $\begin{array}{c}\mathrm{SBP} \geq 130 \mathrm{mmHg} \text { and } \\
\mathrm{DBP} \geq 85 \mathrm{mmHg}\end{array}$ & 103 (38.4\%) & 103 (38.4\%) \\
\hline \multicolumn{3}{|l|}{ BMI $\left(\mathrm{kg} / \mathrm{m}^{2}\right)$} \\
\hline$<18.5$ & $50(18.7)$ & \\
\hline $18.5-24.9$ & $184(68.7)$ & \\
\hline$\geq 25$ & $34(12.7)$ & \\
\hline \multicolumn{3}{|l|}{ WC } \\
\hline Male $\geq 102 \mathrm{~cm}$ & $2(0.7)$ & \\
\hline Female $\geq 88 \mathrm{~cm}$ & $48(17.9)$ & $50(18.7)$ \\
\hline $\mathrm{FBG} \geq 100 \mathrm{mg} / \mathrm{dl}$ & $46(17.2)$ & $46(17.2)$ \\
\hline $\mathrm{TC} \geq 200 \mathrm{mg} / \mathrm{dl}$ & $67(25.0)$ & \\
\hline $\begin{aligned} \mathrm{HDL}-\mathrm{c} & \leq 40 \mathrm{mg} / \mathrm{dl} \text { male } \\
\text { and } & \leq 50 \mathrm{mg} / \mathrm{dl} \text { female }\end{aligned}$ & $132(49.3)$ & $132(49.3)$ \\
\hline $\mathrm{TGs} \geq 150 \mathrm{mg} / \mathrm{dl}$ & $80(29.9)$ & $80(29.9)$ \\
\hline $\mathrm{LDL}-\mathrm{c} \geq 100 \mathrm{mg} / \mathrm{dl}$ & $101(37.7)$ & \\
\hline
\end{tabular}

$S B P$ systolic blood pressure, $D B P$ diastolic blood pressure, $B M I$ body mass index, WC waist circumference, FBG fasting blood glucose, $T C$ total cholesterol, $H D L$ high density lipoprotein-cholesterol, TGs triglycerides, $L D L$ low density lipoprotein-cholesterol
41-50 years and those not enrolled in formal education were significantly associated with $\mathrm{MS}(\mathrm{COR}=3.171$, 95\% CI 1.268-7.928, and COR $=0.384$, 95\% CI 0.1790.827 ) respectively. In addition, monthly income level above 2501 ETB (COR = 4.141, 95\% CI 1.007-17.02) was also associated with MS. Moreover, physical activity $(\mathrm{COR}=0.558,95 \% \mathrm{CI} 0.312-0.999)$, duration of HIV diagnosis less than 5 years $(\mathrm{COR}=0.286,95 \%$ CI $0.151-$ $0.543)$, body mass index $\geq 25 \mathrm{~kg} / \mathrm{m}^{2}(\mathrm{COR}=10.47,95 \%$ CI 3.513-31.24), duration of ART regimens for more than 6 years $(\mathrm{COR}=3.011,95 \%$ CI 1.676-5.410), and type of cART regimens $(\mathrm{COR}=2.927,95 \% \mathrm{CI} 1.635-$ 5.238) were significantly associated with MS.

Multivariable logistic regression analysis was done for all explanatory variables with $\mathrm{p}<0.25$ in bivariate logistic regression analysis. Accordingly, those not enrolled in formal education and body mass index above $25 \mathrm{~kg} / \mathrm{m}^{2}$ were independent predictors of MS. Therefore, those who were not enrolled in formal education were less likely to have MS (AOR $=0.252$, 95\% CI 0.072-0.879) and overweight patients were 13.4 times more likely to have MS $(\mathrm{AOR}=13.398,95 \%$ CI 3.943-45.525) (Table 4).

\section{Discussion}

In this study, the prevalence of MS was 23.5, 20.5 and $27.6 \%$ by NCEP-ATP III, IDF and JIS respectively. The JIS result of MS in our finding was higher than the others two. This finding was consistent with the study conducted in Malaysia (26.5, 37.4 and 43.4\%) [13] and South Africa (24.1, 25.5, and 28.2\%) respectively [14]. The prevalence of MS according to JIS in our study was in closer to the finding from South Africa i.e. 28.2\% [14]. NCEPATP III did not use any single risk factor (e.g. abdominal obesity) as a requirement for MS diagnosis. The IDF clinical definition thus uses the presence of abdominal obesity necessary for diagnosis. If this is the case, 2 additional factors originally listed in the NCEP-ATP III definition are sufficient to diagnose MS [15]. This makes variation in NCEP-ATP III and IDF definition of MS.

Based on NCEP-ATP III criteria, our finding was higher than results obtained from Darlinghurst and Southern Brazil, in which the prevalence of MS was 18, 17.2\% respectively $[16,17]$. Our finding was also higher than the study from Hawassa University Referral Hospital and Jimma University specialized hospital, where the prevalence of MS was 18.1 and $21.1 \%$ respectively $[18,19]$. This variation might be due to the fact that, there were higher numbers of participants with low HDL and high blood pressure in our study. The other possible explanation might be our study was done in primary health care setting unlike that of Hawassa and JUSH, which are referral settings with high level of care and professional profile. On the other hand, our finding was in line with the study 
Table 4 Predictors of MS among PLWHIV at follow up in Jimma health centre ART clinic, April 01 to May 30, 2016

\begin{tabular}{|c|c|c|c|c|c|c|}
\hline \multirow[t]{3}{*}{ Variables } & \multirow{2}{*}{\multicolumn{2}{|c|}{$\begin{array}{l}\text { MS according to } \\
\text { (NCEP-ATP III) }\end{array}$}} & \multicolumn{2}{|c|}{ Bivariate analysis } & \multicolumn{2}{|c|}{ Multivariate analysis } \\
\hline & & & \multirow{2}{*}{ p value } & \multirow[t]{2}{*}{ COR $(95 \% \mathrm{Cl})$} & \multirow[t]{2}{*}{$p$ value } & \multirow[t]{2}{*}{ AOR $(95 \% \mathrm{Cl})$} \\
\hline & Yes & No & & & & \\
\hline \multicolumn{7}{|l|}{ Sex } \\
\hline Male & 12 & 45 & 0.623 & $0.837(0.411-1.703)$ & & \\
\hline Female & 51 & 160 & 1 & 1 & & \\
\hline \multicolumn{7}{|l|}{ Age in years } \\
\hline $18-30$ & 8 & 52 & 1 & 1 & 1 & 1 \\
\hline $31-40$ & 24 & 85 & 0.172 & $1.835(0.768-4.387)$ & 0.538 & $1.358(0.513-3.594)$ \\
\hline $41-50$ & 20 & 41 & 0.014 & $3.171(1.268-7.928)$ & 0.175 & $2.058(0.725-5.847)$ \\
\hline$\geq 51$ & 11 & 27 & 0.062 & $2.648(0.953-7.362)$ & 0.344 & $1.782(0.539-5.894)$ \\
\hline \multicolumn{7}{|l|}{ Able to write or read } \\
\hline No & 17 & 79 & 0.097 & $0.589(0.316-1.099)$ & 0.979 & $1.014(0.355-2.899)$ \\
\hline Yes & 46 & 126 & 1 & 1 & 1 & 1 \\
\hline \multicolumn{7}{|l|}{ Formal education } \\
\hline Yes & 54 & 143 & 1 & 1 & 1 & 1 \\
\hline No & 9 & 62 & 0.014 & $0.384(0.179-0.827)$ & 0.031 & $0.252(0.072-0.879)$ \\
\hline \multicolumn{7}{|l|}{ Smoking history } \\
\hline No & 61 & 192 & 1 & 1 & & \\
\hline Yes & 2 & 13 & 0.349 & $0.484(0.106-2.206)$ & & \\
\hline \multicolumn{7}{|l|}{ Past Khat chewer } \\
\hline No & 46 & 133 & 1 & 1 & 1 & 1 \\
\hline Yes & 17 & 72 & 0.232 & $0.683(0.365-1.277)$ & 0.583 & $0.813(0.388-1.704)$ \\
\hline \multicolumn{7}{|c|}{ Current Khat chewer } \\
\hline No & 14 & 58 & 1 & 1 & & \\
\hline Yes & 3 & 14 & 0.865 & $0.888(0.224-3.517)$ & & \\
\hline \multicolumn{7}{|c|}{ Alcohol consumption } \\
\hline No & 39 & 127 & 1 & 1 & & \\
\hline Yes & 24 & 78 & 0.995 & $1.002(0.560-1.792)$ & & \\
\hline \multicolumn{7}{|c|}{ Frequency of alcohol } \\
\hline 1-4 days/weeks & 11 & 27 & 1 & 1 & & \\
\hline 1-3 days/weeks & 8 & 30 & 0.428 & $0.655(0.229-1.868)$ & & \\
\hline$<$ Once a month & 5 & 21 & 0.381 & $0.584(0.176-1.943)$ & & \\
\hline \multicolumn{7}{|l|}{ Physical activity } \\
\hline Inactive & 40 & 101 & 1 & 1 & 1 & 1 \\
\hline Active & 23 & 104 & 0.050 & $0.558(0.312-0.999)$ & 0.325 & $0.702(0.347-1.420)$ \\
\hline \multicolumn{7}{|l|}{ Fruit intake } \\
\hline None & 23 & 55 & 1 & 1 & 1 & 1 \\
\hline 1-2 days/week & 27 & 98 & 0.206 & $0.659(0.345-1.258)$ & 0.103 & $0.513(0.230-1.145)$ \\
\hline 3-4 days/week & 9 & 32 & 0.380 & $0.673(0.277-1.630)$ & 0.621 & $0.767(0.269-2.190)$ \\
\hline 5-7 days/week & 4 & 20 & 0.220 & $0.478(0.147-1.554)$ & 0.334 & $0.513(0.132-1.986)$ \\
\hline \multicolumn{7}{|l|}{ Comorbid disease } \\
\hline No & 53 & 187 & 1 & 1 & 1 & 1 \\
\hline Yes & 10 & 18 & 0.112 & $1.960(0.854-4.500)$ & 0.543 & $1.383(0.486-3.930)$ \\
\hline Duration of HIV & & & & & & \\
\hline$\leq 5$ years & 15 & 107 & $<0.001$ & $0.286(0.151-0.543)$ & 0.136 & $0.482(0.185-1.259)$ \\
\hline$>5$ years & 48 & 98 & 1 & 1 & 1 & 1 \\
\hline CD4 (cell/mm³) & & & & & & \\
\hline$<350$ & 53 & 170 & 1 & 1 & & \\
\hline $351-550$ & 9 & 29 & 0.991 & $0.995(0.443-2.235)$ & & \\
\hline$\geq 551$ & 1 & 6 & 0.566 & $0.535(0.063-4.541)$ & & \\
\hline
\end{tabular}


Table 4 continued

\begin{tabular}{|c|c|c|c|c|c|c|}
\hline \multirow[t]{3}{*}{ Variables } & \multirow{2}{*}{\multicolumn{2}{|c|}{$\begin{array}{l}\text { MS according to } \\
\text { (NCEP-ATP III) }\end{array}$}} & \multicolumn{2}{|c|}{ Bivariate analysis } & \multicolumn{2}{|c|}{ Multivariate analysis } \\
\hline & & & \multirow{2}{*}{$p$ value } & \multirow{2}{*}{ COR $(95 \% \mathrm{Cl})$} & \multirow{2}{*}{$p$ value } & \multirow{2}{*}{ AOR $(95 \% \mathrm{Cl})$} \\
\hline & Yes & No & & & & \\
\hline \multicolumn{7}{|l|}{ WHO stages } \\
\hline Stage I & 12 & 35 & 1 & 1 & & \\
\hline Stage II & 28 & 101 & 0.592 & $0.809(0.371-1.760)$ & & \\
\hline Stage III & 21 & 63 & 0.946 & $0.972(0.428-2.209)$ & & \\
\hline Stage IV & 2 & 6 & 0.975 & $0.972(0.172-5.481)$ & & \\
\hline \multicolumn{7}{|c|}{ Duration of CART } \\
\hline$\leq 5$ years & 26 & 137 & 1 & 1 & 1 & 1 \\
\hline$>5$ years & 36 & 63 & $<0.001$ & $3.011(1.676-5.410)$ & 0.372 & $1.563(0.586-4.173)$ \\
\hline Others $^{a}$ & 1 & 5 & 0.963 & $1.054(0.118-9.394)$ & 0.735 & $1.499(0.143-15.666)$ \\
\hline \multicolumn{7}{|c|}{ Types of cART } \\
\hline D-drugs ${ }^{b}$ & 33 & 56 & $<0.001$ & $2.927(1.635-5.238)$ & 0.366 & $1.591(0.581-4.360)$ \\
\hline Others $^{c}$ & 30 & 149 & 1 & 1 & 1 & 1 \\
\hline \multicolumn{7}{|l|}{ BMI $\left(\mathrm{kg} / \mathrm{m}^{2}\right)$} \\
\hline$<18.5$ & 6 & 44 & 1 & 1 & 1 & 1 \\
\hline $18.5-24.9$ & 37 & 147 & 0.195 & $1.846(0.731-4.660)$ & 0.129 & $2.191(0.795-6.036)$ \\
\hline$\geq 25$ & 20 & 14 & $<0.001$ & $10.47(3.513-31.24)$ & $<0.001$ & $13.398(3.943-45.525)$ \\
\hline
\end{tabular}

COR crude odd ratio, $A O R$ adjusted odd ratio, HIV human immunodeficiency virus, $C D 4$ cluster determinant 4 , WHO world health organization, $C A R T$ combination antiretroviral therapy, $B M I$ body mass index, $d 4 T$ stavudine, 3TC lamivudine, AZT zidovudine, TDF tenofovir, NVP nevirapine, EVF efavirenz

a Naïve patients

b $\mathrm{d} 4 \mathrm{~T}+3 \mathrm{TC}+\mathrm{NVP} / \mathrm{or} E V F$

c $\mathrm{AZT} /$ or TDF $+3 \mathrm{TC}+\mathrm{NVP} /$ or EVF and naïve patients

from Thailand in which $22.2 \%$ of participants had MS [5]. Our finding was lower than the results obtained from Danish, where 27\% of the participants were found to be victims of MS [20]. This difference might be due to the variation in different components of MS (WC, high FBG and TGs) which was lower in our study and the small sample size utilized in our study.

The prevalence of MS using IDF criteria in our study was higher than the study conducted in Darlinghurst (i.e. 14\%) [16]. This variation might be due to the higher proportions of women (78.7\%) in our study and WC can be considered as basic parameters for MS diagnosis in IDF criteria. However, the Darlinghurst study considered only men patients. In contrary, the prevalence of MS using IDF criteria in our finding was lower than the finding from Hawassa university referral hospital [18]. This discrepancy might be due to use of abdominal obesity as basic requirement for diagnosing MS by IDF criteria. There were lower proportions of patients that had high abdominal obesity in our finding.

This study revealed that, being enrolled in formal education was independent predictor of MS. Similar finding was also reported from Nairobi [21]. This could be justified by the higher proportions (72.8\%) of patients' enrolled in formal education were receiving D-drugs, which were well known risk of MS as reported by other study [18]. The prevalence of MS increased with age [22], but age groups were not predictors of MS in our finding, unlike reports from Hawassa University referral hospital and Nairobi $[18,21]$. This difference might be due to variation in age group (i.e. more than three-fifth of them had $<40$ years old in our study).

The participant's characteristics like smoking habit, alcohol consumption, physical activity and Khat chewing were not identified as independent predictors' of MS. This was consistent with finding from Hawassa University referral hospital [18]. This study also showed that, body mass index of $\geq 25 \mathrm{~kg} / \mathrm{m}^{2}$ was independent predictor of MS. This was in line with the study done in Hawassa University referral hospital [18].

The most frequently observed features of abnormalities were lower HDL (49.3\%), raised BP (38.4\%) and raised LDL (37.7\%), while TGs (29.9\%), TC (18.7\%) and FBG (17.2\%) were less common.

The development of cART-associated MS is complex and a number of factors including direct effects of ART on lipid metabolism, endothelial and adipocyte cell function, and mitochondria [23] could be implicated. Cumulative evidence has pointed out the relationship between different metabolic disorders and cART use, including 
insulin resistance, hyperlipidemia, and lipodystrophy, even though it remains controversial whether this effect can be directly ascribed to cART [24]. Although capturing the impact on duration of specific drug on the development of MS could be impossible, it seemed cART duration could have an impact. This might be hypothesized by our finding that, patients who received cART more than 5 years has $15.6 \%$ higher odds of having MS than those below 5 year, although our finding lacked statistical significance. Similar results were reported by study done in Hawassa University referral hospital [18]. In contrast, study done in Jimma University specialized hospital had witnessed the impact of long term exposure (> 12 months) of cART on MS [19]. This difference might be due to variation in years of cART duration categories in the statistical analysis. Likewise, the odds of having MS was increased by $15.9 \%$ among patients' treated with D-drugs, however, the difference was statistically insignificant. The study conducted in Hawassa University referral hospital, showed that receiving D4T - 3TC - EFV regimen was significantly associated with higher odds of MS [18].

As one of its strength, this study tried to high light the prevalence and some of the risk factors of MS in low income settings, which was not fully understood in HIV-infected patients. However, the anticipation of early diagnosis for its components should be part of the good clinical practices. Consequently, doing so might contribute to slow or even reduce its impact on the development of CVD. However, our study had some limitation. Being a single center study and focused on primary care setting could affect the generalizability.

\section{Conclusions}

Metabolic syndromes were relatively common to HIV/ AIDS patients in a primary care setting. In our finding one in four of the study participants had MS. Low level of HDL-c and high BP as a component of the five MS criteria were more prevalent in our study population. The study revealed that enrollment in formal education and overweight were independent predictors of MS.

\footnotetext{
Authors' contributions

DDB conceived and led the study acquisition of data, interpretation of data, performed the statistical analysis and revised manuscript for intellectual content, edited the manuscript; LD conceived and led the study acquisition of data, performed statistical analysis, revised manuscript for intellectual content; TAM assisted with interpretation of data, performed statistical analysis, drafted the manuscript, edited the manuscript; MGT, DAA interpretation of data, and revised manuscript for intellectual content; TCE conceived and led the study acquisition of data, interpretation of data, performed the statistical analysis. All authors read and approved the final manuscript.

\section{Author details}

${ }^{1}$ Department of Pharmacy, Faculty of Health Sciences, Institute of Health, Jimma University, Jimma, Ethiopia. ${ }^{2}$ Department of Epidemiology, Public Health Faculty, Institute of Health, Jimma University, Jimma, Ethiopia.
}

${ }^{3}$ Department of Medical Laboratory, Jimma University Medical Centre, Institute of Health, Jimma University, Jimma, Ethiopia.

\section{Acknowledgements}

We would like to thank the participants, and the data collectors (nurses and laboratory technologists of Jimma health center) for their immense contribution of this work. Our heartfelt gratitude should also go to Jimma University for facilitating this study.

\section{Competing interests}

The authors declare that they have no competing interests.

\section{Availability of data and materials}

The original data of this study could be available for the third body only up on author's request.

\section{Consent for publication}

No applicable.

\section{Ethics approval and consent to participate}

Ethical approval was obtained from the Institutional Review Board of the College of Health Science, Jimma University, Jimma, Ethiopia. Informed consent was obtained from all participants to conduct the study.

\section{Funding}

Not applicable.

\section{Publisher's Note}

Springer Nature remains neutral with regard to jurisdictional claims in published maps and institutional affiliations.

Received: 30 October 2017 Accepted: 12 February 2018

Published online: 21 February 2018

\section{References}

1. Iloh GUP, Okafor GOC, NkwaAmadi A. Epidemiology of metabolic syndrome among adult Nigerians in a rural hospital in Eastern Nigeria. Sci J Public Health. 2014;2:135-43.

2. Alberti KG, Zimmet P, Shaw J. Metabolic syndrome-a new world-wide definition. A consensus statement from the international diabetes federation. Diabet Med. 2006;23:469-80.

3. Miranda PJ, Defronzo RA, Califf RM, Guyton JR. Metabolic syndrome: definition, pathophysiology and mechanisms. Am Heart J. 2005;149:33-45.

4. Jerico C, Knobel H, Montero M, Ordonez-Llanos J, Guelar A. Metabolic syndrome among HIV-infected patients: prevalence, characteristics, and related factors. Diabetes Care. 2005:28:144-9.

5. Jantarapakde J, Phanuphak N, Chaturawit C, Pengnonyang S, Mathajittiphan P, Takamtha P, et al. Prevalence of metabolic syndrome among antiretroviral-naive and antiretroviral-experienced HIV-1 infected Thai adults. AIDS Patient Care STDs. 2014;28:7

6. Mondy K, OvertonET Grubb J, Tong S, Seyfried W, Powderly W, et al. Metabolic syndrome in HIV-infected patients from an urban, midwestern US outpatient population. Clin Infect Dis. 2007:44:726-34.

7. Ford ES, Giles WH. Prevalence of the metabolic syndrome among US adults: findings from the third National Health and Nutrition Examination Survey. JAMA. 2004;287:356-9.

8. Sobieszczyk ME, Hoover DR, Anastos K, Mulligan K, Tan T, Shi Q, et al, Prevalence and predictors of metabolic syndrome among HIV-infected and HIV uninfected women in the women's interagency HIV study. J Acquir Immune Defic Syndr. 2008;48:272-80.

9. Dimodi HT, EtameLS Nguimkeng BS, Mbappe FE, Ndoe NE, Tchinda JN, et al. Prevalence of metabolic syndrome in HIV-infected Cameroonian patients. World J AIDS. 2014;4:85-92.

10. World Health Organization. WHO STEPS instrument (core and expanded) The WHO STEPwise approach to noncommunicable disease risk factor surveillance. Geneva: World Health Organization; 2010. 
11. World Health Organization. WHO STEPS instrument. Geneva: World Health Organization; 2012.

12. Expert Panel on Detection E. Executive summary of the third report of the national cholesterol educational program (NCEP) expert panel on detection, evaluation and treatment of high cholesterol in adults (Adult treatment III). JAMA. 2005;285:2486-97.

13. Ramli AS, Daher AM, Nor-Ashikin MNK, Mat-Nasir N, Ng KK, Miskan M, et al. JIS definition identified more Malaysian adults with metabolic syndrome compared to the NCEP-ATP III and IDF criteria. Biomed Res Int. 2013;2013:1-10.

14. Nguyen KA, Peer N, Villiers A, Mukasa B, Matsha TE, Mills EJ, et al. Metabolic syndrome in people living with human immunodeficiency virus: an assessment of the prevalence and the agreement between diagnostic criteria. Int J Endocrinol. 2017;2017:1-8.

15. Grundy SM, Cleeman JI, Daniels SR, Donato KA, Eckel RH, Franklin BA, et al. Diagnosis and management of the metabolic syndrome: an American Heart Association/National Heart, Lung and Blood Institute scientific statement. Circulation. 2005;112:2735-52.

16. Samaras K, Wand H, Law M, Emery S, Cooper D, Carr A. Prevalence of metabolic syndrome in HIV-infected patients receiving highly active antiretroviral therapy using International Diabetes Foundation and Adult Treatment Panel III Criteria. Diabetes Care. 2007:30:113-9.

17. Alencastro PR, Fuchs SC, Wolff FH, Ikeda ML, Brandão AB, Barcellos NT. Independent predictors of metabolic syndrome in HIV-infected patients. AIDS Patient Care STDs. 2011;25:11.
18. Tesfaye DY, Kinde S, Medhin G, Megerssa YC, Tadewos A, Tadesse E, et al. Burden of metabolic syndrome among HIV-infected patients in Southern Ethiopia. Diabetes Metab Syndr Clin Res Rev. 2014;8:102-7.

19. Berhane T, Yami A, Alemseged F, Yemane T, Hamza L, Kassim M, et al. Prevalence of lipodystrophy and metabolic syndrome among HIV positive individuals on highly active anti-retroviral treatment in Jimma, South West Ethiopia. Pan Afr Med J. 2012;13:43.

20. Hansen BR, Petersen J, Haugaard SB, Madsbad S, Obel N, Suzuki Y, et al. The prevalence of metabolic syndrome in Danish patients with HIV infection: the effect of antiretroviral therapy. HIV Med. 2009;10:378-87.

21. Kaduka LU, Kombe Y, Kenya E, Kuria E, Bore JK, Bukania ZN, et al. Prevalence of metabolic syndrome among an urban population in Kenya. Diabetes Care. 2012;35:887-93.

22. Worm SW, Friis-Møller N, Bruyand M, Monforte ADA, Rickenbach M, Reiss $\mathrm{P}$, et al. High prevalence of the metabolic syndrome in HIV-infected patients: impact of different definitions of the metabolic syndrome. AIDS. 2010;24:427-35.

23. Barbaro G. Metabolic and cardiovascular complications of highly active antiretroviral therapy for HIV infection: HAART-associated metabolic syndrome; molecular mechanisms. Curr HIV Res. 2006;4:79-85.

24. Wand H, Calmy A, Carey DL, Samaras K, Carr A, Law MG, et al. Metabolic syndrome, cardiovascular disease and type 2 diabetes mellitus after initiation of antiretroviral therapy in HIV infection. AIDS Patient Care STDs. 2007:21:2445-53

\section{Submit your next manuscript to BioMed Central and we will help you at every step:}

- We accept pre-submission inquiries

- Our selector tool helps you to find the most relevant journal

- We provide round the clock customer support

- Convenient online submission

- Thorough peer review

- Inclusion in PubMed and all major indexing services

- Maximum visibility for your research

Submit your manuscript at www.biomedcentral.com/submit 